\title{
Avaliação Institucional: conceitos, objetivos, participação e implicações para a escola
}

\author{
Evaluación Institucional: conceptos, objetivos, participación e \\ implicaciones para la escuela \\ Institutional Assessment: concepts, objectives, participation and \\ implications for the School
}

\author{
Maria Alice de Freitas Sias ${ }^{1}$ \\ Rosa Maria Martins Carvalho Dutra ${ }^{2}$ \\ Santiago Bretanha - Colaborador ${ }^{3}$ \\ Ana Cristina da Silva Rodrigues - Orientadora ${ }^{4}$
}

\begin{abstract}
Resumo
O presente trabalho integra as atividades do projeto de intervenção "Reflexões sobre o Projeto Político-Pedagógico e a importância de avaliar a escola constantemente" desenvolvido no Mestrado Profissional em Educação da Universidade Federal do Pampa, na Linha de Pesquisa Política e Gestão da Educação. O projeto é realizado na Escola Municipal de Ensino Fundamental Balbino Mascarenhas, da cidade de Pelotas, Estado do Rio Grande do Sul (RS), e possui como enfoque o processo contínuo de avaliação da instituição escolar. O objetivo do trabalho é analisar e avaliar o processo da gestão e do cotidiano escolar da escola citada, criando subsídios para significação e reconstrução do Projeto Político-Pedagógico. Nesse sentido, o estudo sobre a avaliação institucional é de extrema importância, pois tem como propósito identificar as carências da escola e realizar as devidas intervenções, ou seja, usar os resultados da avaliação para qualificar o Projeto Político-Pedagógico, a escola e os sujeitos que dela participam. A avaliação torna-se um instrumento para a busca da qualidade escolar, tendo como principal intenção a concretização, a ação-reflexão-ação de todo o processo educacional. Desse modo, acredita-se que a avaliação institucional deve estar assegurada no Projeto Político-Pedagógico, tendo claros os seus objetivos, indicadores, princípios, finalidades e as concepções de avaliação, que, ao serem realizadas, devem partir do princípio balizador corrigir dificuldades e evitar novas e futuras à instituição escolar.
\end{abstract}

Palavras-chave: Avaliação Institucional, Projeto Político-Pedagógico, Gestão Escolar.

\section{Resumen}

El presente trabajo integra las actividades del proyecto de intervención "Reflexiones sobre el Proyecto PolíticoPedagógico y la" la importancia de evaluar la escuela constantemente", que se desarrolla en el Máster

\footnotetext{
${ }^{1}$ Mestranda em Educação pelo Programa de Pós-Graduação em Educação da Universidade Federal do Pampa (PPGE/UNIPAMPA), campus Jaguarão; Jaguarão, Rio Grande do Sul, Brasil; alicesias @yahoo.com.br.

${ }^{2}$ Mestranda em Educação pelo Programa de Pós-Graduação em Educação da Universidade Federal do Pampa (PPGE/UNIPAMPA), campus Jaguarão; Jaguarão, Rio Grande do Sul, Brasil; rosadutra14@ gmail.com.

${ }^{3}$ (COLABORADOR) Mestrando em Letras pelo Programa de Pós-graduação em Letras da Universidade Católica de Pelotas (PPGL/UCPEL); Pelotas, Rio Grande do Sul, Brasil. santiagobretanha@gmail.com. Bolsista Prosuc I/CAPES.

${ }^{4}$ (ORIENTADORA) Doutora em Educação; Professora Adjunta do Programa de Pós-Graduação em Educação da Universidade Federal do Pampa (PPGE/UNIPAMPA), campus Jaguarão; Jaguarão, Rio Grande do Sul, Brasil; anacristina@unipampa.edu.br.
} 
Profesional en Educación de la Universidad Federal de Pampa, en la Línea de Investigación Politica y Gestión de la Educación. El proyecto es realizado en la Escuela Municipal de Enseñanza Fundamental Balbino Mascarenhas, de la ciudad de Pelotas, Estado de Rio Grande do Sul (RS), y posee como enfoque el proceso continuo de evaluación de la institución escolar. El objetivo del trabajo es analizar y evaluar el proceso de la gestión y del cotidiano escolar de la Escuela citada, creando subsidios para significación y reconstrucción del Proyecto Político-Pedagógico. En ese sentido, el estudio sobre la evaluación institucional es de extrema importancia, pues tiene como propósito identificar las carencias de la escuela y realizar las debidas intervenciones, o sea, usar los resultados de la evaluación para calificar el Proyecto Político-Pedagógico, la escuela y los sujetos que de ella participan. La evaluación se convierte en un instrumento para la búsqueda de la calidad escolar, teniendo como principal intención la concreción, la acción-reflexión-acción de todo el proceso educativo. De ese modo, se cree que la evaluación institucional debe estar asegurada en el Proyecto PolíticoPedagógico, teniendo claros sus objetivos, indicadores, principios, finalidades y las concepciones de evaluación que, cuando sean realizadas, deben tener como principio balizador corregir dificultades y evitar nuevas y futuras a la institución escolar. El presente estudio expone conceptos, objetivos, participación e implicaciones de la Evaluación Institucional en la escuela.

Palabras clave: Evaluación institucional, Proyecto Político-Pedagógico, Gestión Escolar.

\begin{abstract}
This work integrates the activities of the intervention project "Reflections on the Political-Pedagogical Project and the importance of constantly evaluating the school", which is developed in the Professional Master's Degree in Education at the Federal University of Pampa, in the Line of Political Research and Management of Education. The project is carried out in the Municipal School of Basic Education Balbino Mascarenhas, in the city of Pelotas, State of Rio Grande do Sul (RS), and has as its focus the continuous evaluation process of the school institution. The objective of the work is to analyze and evaluate the process of the management and of the daily school life of the School, creating subsidies for the significance and reconstruction of the Political-Pedagogical Project. In this sense, the study on institutional evaluation is extremely important, since its purpose is to identify the shortcomings of the school and carry out the appropriate interventions, that is, to use the results of the evaluation to qualify the Political-Pedagogical Project, the school and the subjects participating in it. Evaluation becomes in an instrument for the search for school quality, having as its main intention the realization, action-reflection-action of the whole educational process. In this way, it is believed that institutional evaluation should be assured in the PoliticalPedagogical Project, having clear objectives, indicators, principles, goals and evaluation conceptions that, when carried out, should have as their guiding principle to correct difficulties and prevent new and future obstacles in the school institutions. This study presents concepts, objectives, participation and implications of Institutional Assessment in the school.
\end{abstract}

Keywords: Institutional Evaluation, Political-Pedagogical Project, School Management.

\title{
1. Introdução
}

O presente trabalho integra as atividades do projeto de intervenção "Reflexões sobre o Projeto Político-Pedagógico e a importância de avaliar a escola constantemente" desenvolvido no Mestrado Profissional em Educação da Universidade Federal do Pampa, na Linha de Pesquisa Política e Gestão da Educação. O projeto é realizado na Escola Municipal de Ensino Fundamental Balbino Mascarenhas, da cidade de Pelotas, Estado do Rio Grande do Sul (RS), e possui como enfoque o processo contínuo de avaliação da instituição escolar. O objetivo do trabalho é analisar e avaliar o processo da gestão e do cotidiano escolar da escola citada, criando subsídios para significação e reconstrução do Projeto Político-Pedagógico.

Nesse sentido, o estudo sobre a avaliação institucional é de extrema importância, pois tem como propósito identificar as carências da escola e realizar as devidas intervenções, ou seja, usar os resultados da avaliação para qualificar o Projeto Político-Pedagógico, a escola e 
os sujeitos que dela participam. A avaliação torna-se um instrumento para a busca da qualidade escolar, tendo como principal intenção a concretização, a ação-reflexão-ação de todo o processo educacional.

Desse modo, acredita-se que a avaliação institucional deve estar assegurada no Projeto Político-Pedagógico, tendo claros os seus objetivos, indicadores, princípios, finalidades e as concepções de avaliação, que, ao serem realizadas, devem partir do princípio balizador corrigir dificuldades e evitar novas e futuras à instituição escolar.

O presente texto é um recorte dos estudos do projeto de intervenção que tem como título, "Reflexões sobre o Projeto Político-Pedagógico e a importância de avaliar a escola constantemente", cujo objetivo geral é analisar e avaliar o cotidiano escolar e os procedimentos da gestão da Escola Municipal de Ensino Fundamental Balbino Mascarenhas, da cidade Pelotas, Estado do Rio Grande do Sul (RS). O projeto de intervenção é desenvolvido no Mestrado Profissional em Educação da Universidade Federal do Pampa (UNIPAMPA) na Linha de Pesquisa Política e Gestão da Educação, e aqui, desdobra-se com a cooperação entre duas pesquisadoras do Programa de Pós-graduação em Educação da UNIPAMPA e de um pesquisador do Programa de Pós-graduação em Letras/Linguística Aplicada da Universidade Católica de Pelotas.

Assim sendo, aqui pretende-se, em uma revisão bibliográfica de cunho exploratório, o refletir sobre a avaliação institucional e a sua importância dentro da instituição escolar, especificamente para a avaliação e para a qualificação do Projeto Político-Pedagógico (PPP) da escola. Segundo Gil $(2007$, p.43) "a pesquisa bibliográfica é feita a partir do levantamento de referências teóricas já analisadas, e publicadas por meios escritos e eletrônicos”, e, visto que é exploratória, "tem como objetivo proporcionar maior familiaridade com o problema, com vistas a torná-lo mais explícito ou a construir hipóteses”. Desse modo, a intenção aqui materializada é sumariamente teórica, voltada à compreensão da avaliação em sua complexidade e em seus impactos para a Educação Básica.

\section{Princípios teóricos}

Segundo informação do INEP/CONAES, disposta no site da Gerência de Avaliação Institucional da Universidade Estadual de Goiás, a avaliação institucional “[...] é um processo sistemático de identificação de méritos e de valores, de fatos e de expectativas; é uma atividade complexa que envolve: múltiplos instrumentos; diferentes momentos; diferentes agentes" (GERÊNCIA... 2011?, s/p). 
A avaliação institucional é um meio de investigação, em busca de solucionar os problemas existentes na escola, estabelecendo propósitos e objetivos, evidenciando as soluções e efetivando a realização, em busca da melhoria, no que foi diagnosticado, como sendo contratempo. Ainda, para Gadotti (2010, p. 1, grifo do autor), “[...] a avaliação institucional tornou-se preocupação essencial para a melhoria dos serviços das escolas e universidades e para a conquista de maior autonomia".

O principal objetivo da avaliação institucional é qualificar o processo educacional, levando em consideração o processo de ensino-aprendizagem dos educandos e, consequentemente, avaliando e qualificando o Projeto Político-Pedagógico, documento este balizador das ações da escola.

Da mesma forma, de acordo com Gadotti (2010, p.13, grifos do autor):

[...] a avaliação institucional e escolar coloca em evidência o projeto institucional, os fins da educação e as concepções pedagógicas, ela se constitui num momento privilegiado de discussão do projeto político-pedagógico da escola.

A participação da comunidade escolar é de extrema importância para a avaliação institucional. O processo deve acontecer juntamente com os alunos, professores, pais, funcionários e equipe diretiva, envolvendo toda a comunidade, efetivando, assim, a (re)construção e a avaliação do PPP.

Segundo Melchior (2004), para obter-se a qualidade que tanto se quer na educação, é necessário conquistar um grande número de sujeitos da comunidade escolar para participar, principalmente, dos momentos de avaliação da escola, tendo como meta principal a mudança do processo educativo.

A avaliação institucional deve ser vista como um instrumento que acompanha as atividades da escola, em um processo contínuo de forma a elaborar, ajustar e qualificar os projetos da instituição, na qual, devem estar sinalizados na proposta central da escola e no PPP, efetuando assim, as alterações quando necessárias.

Avaliar a Educação Básica significa atribuir aos gestores responsabilidades e critérios para a realização de uma avaliação criteriosa e séria que leve em conta as discussões de todo o grupo e aponte, através do anúncio de uma concepção de educação, o lugar que se deseja ocupar na educação de seus integrantes (MALAVASI, 2010, p. 87).

De acordo com Melchior (2004), na avaliação democrática, não se pode pensar em avaliar apenas o aluno, o professor, ou o aluno e o professor: tem-se que efetivar a avaliação do todo da instituição escolar, pois existem muitas outras questões que "desorganizam" o processo 
educacional e que, por isso, devem ser avaliadas da mesma forma. Quanto mais ampla for a avaliação, mais qualificada a escola se tornará, levando assim, à contínua qualificação da instituição. Nas palavras de Melchior,

[p]ensar em educação de qualidade implica pensar em democratização dos espaços institucionais educativos e de reconhecer, de forma consciente e reflexiva, os erros institucionais que vêm acontecendo no decorrer dos tempos, sem deixar de perceber os vínculos que existem entre participação, avaliação e inovações que vão gerá-la (MELCHIOR, 2004, p. 16).

De mesmo modo, Luckesi (1997, p. 17) reafirma essa visão ao salientar que “[...] não [possui] dúvidas sobre o potencial transformador da avaliação, na medida em que a sua função é subsidiar a busca dos resultados mais satisfatórios possíveis”. Esse é o propósito básico da avaliação institucional, desde que ela seja pautada por uma perspectiva-ação democrática, reflexiva, crítica e flexível. Conforme Santos Guerra (1993, p. 104), “[...] se existe um desejo de fazer uma avaliação é porque existe uma preocupação com a qualidade do trabalho e com as estratégias de melhora".

Quando se alude sobre o processo de qualificação da escola, corrobora-se também, sobre a qualificação dos seus profissionais, pois no momento em que se qualifica as ações do espaço, qualificam-se também os sujeitos, de modo que se tornam importantes as reflexões sobre as suas próprias ações. Dessa maneira, o papel fundamental do avaliador é o de

subsidiar e fornecer informações relevantes ao processo de tomada de decisão dos indivíduos envolvidos nos programas para melhoria da qualidade da educação. A avaliação é parte integrante da organização escolar e do desenvolvimento curricular. Isto tanto para os administradores usarem os resultados para orientar suas ações, no sentido de estimular e fomentar iniciativas voltadas para a melhoria da qualidade da educação, como para cada um, individualmente, fazer sua auto-avaliação e buscar a autoqualificação (MELCHIOR, 2004, p. 34).

Pensando desse modo, é possível conceber que a avaliação institucional organiza a escola a partir de diagnósticos visando a construção de novos planejamentos e projetos em prol de novos objetivos, tendo como principal intuito a qualificação da instituição como um todo. Dessa maneira, a avaliação é fundamentalmente diagnóstica, no sentido que é um "instrumento dialético do avanço, terá de ser o instrumento de identificação de novos rumos. Enfim, terá de ser o instrumento do reconhecimento dos caminhos percorridos e da identificação dos caminhos a serem perseguidos" (LUCKESI, 1995, p. 43).

Assim, além de diagnosticar as necessidades evidenciadas pela avaliação, a gestão escolar deve providenciar meios para que essas sejam sanadas, de forma que consiga eliminar 
as causas para tais carências; de nada serve conhecer os problemas da instituição escolar se não forem tomadas as devidas decisões, tendo como, objetivo transformar a realidade escolar. Nesse contexto, conforme Libâneo (2008, p. 237), “[...] faz-se necessário uma coleta de dados e informações, por meio de diferentes instrumentos de verificação, para saber se os objetivos previstos estão sendo atingidos". Frente a isso, a avaliação institucional tem grande importância para o PPP, uma vez que é fundamental sua contínua avaliação, retomando-se sua filosofia, objetivos, finalidade, pressupostos e as metas da escola.

Ao elaborar o PPP e ao avaliar a instituição, a escola projeta suas intencionalidades, aquilo que deseja e pretende realizar tendo como intenção atender demandas e ir em busca de uma escola melhor para a sua comunidade, levando-a a um processo de autonomia das ações no cotidiano escolar. Nesse contexto, o PPP é um projeto que orienta as atividades educativas futuras, estabelecendo finalidades e metas a serem cumpridas. Veiga, (2006) entende o PPP como a sistematização do trabalho educativo em sua totalidade, no sentido de que

todo projeto supõe rupturas com o presente e promessas para o futuro. Projetar significa tentar quebrar um estado confortável para arriscar-se, atravessar um período de instabilidade e buscar uma nova estabilidade em função da promessa que cada projeto contém de estado melhor do que o presente. Um projeto educativo pode ser tomado como promessa frente a determinadas rupturas. As promessas tornam visíveis os campos de ação possível, comprometendo seus atores e autores (GADOTTI, 1994, p. 579, grifos do autor).

Reafirma-se o propósito da avaliação institucional: qualificar a escola como um todo, a todo o momento e não somente em determinados períodos, de forma coletiva com a comunidade escolar. Ela pode ser sugerida pelos próprios participantes da escola, tendo como intuito reconhecer as dificuldades, evidenciar soluções e administrar as ações, com base nas correções. Assim, o grande objetivo, ao avaliar a escola básica, é renovar e levar adiante cada vez com mais qualidade as metas do Projeto Pedagógico organizado pela comunidade escolar, sem deixar de considerar seu contexto e sua história institucional (MELCHIOR, 2004, p.81).

Desta forma, para que a avaliação institucional aconteça de forma efetiva, é importante o consentimento de todos que fazem parte da comunidade escolar, professores, alunos, pais, gestores, esta aceitação não acontece de forma rápida, à mesma deve ser exposta, indicando os objetivos e benefícios que trará à instituição. Nas palavras de Gadotti (2010, p. 3), “[...] o envolvimento e a participação dos professores, pais, alunos e a comunidade é fundamental para dar credibilidade e legitimidade ao processo de avaliação do sistema educacional".

Essa aceitação só acontecerá se a instituição escolar mobilizar os sujeitos para a efetiva participação. Para tanto, devem ser realizadas reuniões periódicas apresentando à comunidade 
escolar a importância da avaliação institucional, o porquê de sua realização, seus objetivos, propostas, procedimentos, assim como as ações a serem realizadas após a avaliação, de forma que a comunidade compreenda a necessidade e a importância desta ação para a instituição escolar.

\footnotetext{
Para a realização da avaliação institucional pressupõe-se que todos, participantes e avaliadores, tenham o mesmo juízo sobre o funcionamento da instituição, o conceito de qualidade sobre o que se pretende alcançar. Isso se consegue através de liderança eficiente que oportuniza o diálogo, favorece a participação e o comprometimento dos atores do processo (MELCHIOR, 2004, p. 35).
}

Após a apresentação das finalidades da avaliação institucional, a comunidade escolar tem que estar disposta a participar, de maneira objetiva e consciente, da elaboração, execução, da mesma forma, assim como das análises dos dados obtidos. Para tal, é necessário considerar a realidade da comunidade escolar de forma que os avaliadores conheçam a escola avaliada e os sujeitos que estão sendo avaliados - conhecer o todo da escola é extremamente importante para uma avaliação fidedigna e coerente. No processo de avaliação escolar, é imprescindível a autonomia e a autorreflexão dos sujeitos, em que estes tenham condições de avaliar suas próprias ações e para tal, a autoavaliação deve fazer parte deste processo, da própria avaliação.

\footnotetext{
De igual modo, a avaliação institucional deve ter em consideração todos os aspectos da vida da escola, no que diz respeito às estruturas, aos órgãos de administração e gestão, aos meios e recursos, às finalidades educativas, aos currículos, às formas de participação de todos os actores educativos e suas práticas, aos constrangimentos, às políticas, às expectativas e necessidades, aos valores e representações, às dimensões materiais e simbólicas, às relações interpessoais e às interacções com o Estado, com a sociedade e com o meio local, aos sucessos e insucessos, aos percursos realizados e aos projectos de futuro (ESTEBAN, 2008, p. 44).
}

A avaliação institucional implica para as escolas, ou âmbitos maiores, como as universidades, a cultura da mudança, do "querer mudar" em vistas de qualificar os processos educativos da instituição. Esse "querer mudar" só acontecerá quando a comunidade escolar sentir a necessidade de fazer avançar o processo educacional, desenvolvimento que nunca é rápido, pelo contrário, é gradual e lento, e que de forma alguma pode ser negligenciado.

Entretanto, como aponta Melchior (2004), para que as instituições escolares mudem é necessária a participação efetiva do Estado por meio de políticas governamentais, oferecendo condições físicas, materiais, estruturais para a escola e seus funcionários. Ainda, para o mesmo, outros fatores são relevantes, como a vontade de mudar, desenvolvimento dos profissionais, atividades compartilhadas com a comunidade escolar, dedicação, firmeza, iniciativa e respeito ao tempo de impactar/envolver toda a comunidade em prol dessa iniciativa. 


\section{Conclusões}

Portanto, a avaliação institucional é imprescindível e deve ser pensada como um processo, e não como um fim: deve-se pensar no fim como ações a ser elaboradas e executadas em busca de certos resultados. Frente a isso, a avaliação institucional tem por finalidade realizada em prol de resultados positivos, precisa tornar os resultados da avaliação em um processo público, não restrito à instituição.

Nesse sentido, os resultados do processo de avaliação não são apenas responsabilidade da gestão escolar, dos alunos ou dos professores, mas sim de toda comunidade, sendo o sucesso ou fracasso não restrito a um grupo da escola, mas de todos os participantes do grupo escolar. Em consonância, Melchior (2004, p. 40) afirma que "[...] a busca da melhoria da qualidade institucional exige espaço de aperfeiçoamento individual de cada componente do grupo e coletivo nas ações que são de responsabilidade do grupo como um todo".

Desde modo, a avaliação só terá sentido, se todo o processo for realizado em conformidade, havendo ligações coerentes entre os objetivos, propósitos, resultados e ações. Os resultados da avaliação institucional têm como destino a qualificação do processo educacional como um todo identificando as necessidades, imprecisões, e persegue a qualidade no processo educacional, este por fim, evidenciará no processo de ensino-aprendizagem dos seus educandos.

Para efetivar a participação da comunidade escolar, é imprescindível que a instituição realize um chamamento para a participação de toda a comunidade, mobilizando assim, a participação de todos em todos os projetos elaborados, como também na construção, efetivação e avaliação do PPP, desta forma efetivando-se a avaliação institucional.

O que se deseja com a avaliação institucional em âmbito maior é a melhoria de metas e qualidade do ensino, e progressão de princípios democráticos, embasados na autonomia dos alunos, professores e comunidade escolar, levando à autorreflexão. Assim, a avaliação institucional é um processo consecutivo, lento e amplo, e, acima de tudo, complexo, que gera profundos impactos nos PPP.

\section{Referências}

ESTEBAN. Maria Teresa. Escola, currículo e avaliação. 3. Ed. São Paulo: Cortez, 2008.

GADOTTI, M. Pressupostos do projeto pedagógico. Anais da Conferência Nacional de Educação para Todos. Brasília: MEC, 1994. 
Avaliação Institucional: Necessidades e condições para sua realização. DRB

Assessoria. 2010. Disponível em: http://www.drb-

assessoria.com.br/Avali_Institucional.pdf.>. Acesso em: 16 jan. 2017.

GIL, A.C. Como elaborar projetos de pesquisa. 4 ed. São Paulo: Atlas, 2007.

INEP. Instituto Nacional de Estudos e Pesquisas Educacionais Anísio Teixeira. Índice de Desenvolvimento da Educação Básica, 05 set. 2009. Disponível em:

<http://ideb.inep.gov.br/resultado/resultado/resultado.seam?cid=1703156>. Acesso em: 26 jul. 2017.

LIBÂNEO, J. C. Organização e gestão na escola. Goiânia: Alternativa, 2008.

LUCKESI, C. C. Avaliação da aprendizagem escolar. São Paulo: Cortez, 1995.

Avaliação da aprendizagem escolar. 6 ed. São Paulo. Cortez, 1997.

MALAVASI, M. M. S. Avaliação Institucional de qualidade potencializada pela participação dos vários segmentos da escola. In: DALBEN, Â. I. L. de F. et al. (Org.). Convergências e tensões no campo de formação e do trabalho docente. Belo Horizonte: Autêntica, 2010.

MELCHIOR, M. C. Avaliação Institucional da escola básica. Porto Alegre: Premier, 2004.

SANTOS GUERRA, Miguel Àngel. Evaluación: un proceso de diálogo, comprensión y mejora. Málaga: Ediciones Aljibe, 1993.

VEIGA, Ilma Passos Alencastro. Projeto Político-Pedagógico da escola: uma construção coletiva. In: VEIGA, Ilma Passos Alencastro (Org.). Projeto político-pedagógico da escola: uma construção possível. 22.ed. Campinas, SP: Papirus, 2006. 